\title{
Evaluación externa de la calidad analítica en hematología: una necesidad en América Latina
}

\author{
Nilda E. Fink, ${ }^{1}$ Alejandra Fernández Alberti ${ }^{1}$ y Daniel Mazziotta ${ }^{2}$
}

RESUMEN La garantía de calidad analítica de un laboratorio clínico se logra mediante un sistema de control de calidad interno complementado por un programa de evaluación externa. Esa garantía es la base que fundamenta la confiabilidad de los resultados obtenidos por los laboratorios y su uso en el diagnóstico y tratamiento de las enfermedades. En los países de América Latina hay muchos laboratorios que no cuentan con sistemas apropiados de evaluación y control de la calidad. Dada la importancia de los diagnósticos basados en datos hematológicos, durante el XI Congreso Latinoamericano de Bioquímica Clínica (México, 1993) la Organización Panamericana de la Salud patrocinó un curso de control de la calidad en hematología en el que participaron Argentina, Chile, Cuba, México, Paraguay, República Dominicana y Uruguay. Como parte del curso se produjeron materiales de control: solución estándar secundario de cianmetahemoglobina (HICN), solución concentrada estabilizada de hemoglobina $(\mathrm{Hb})$ y sangre entera humana preservada con seudoleucocitos. Estos materiales fueron enviados a laboratorios de los siete países participantes para su uso en procedimientos analíticos, con objeto de llevar a cabo posteriormente una evaluación externa del desempeño individual y de la comparabilidad de los resultados en conjunto. Las tareas asignadas fueron: 1) determinación de hemoglobina, hematocrito, y glóbulos rojos y blancos con los métodos en uso en cada laboratorio; 2) registro de los datos obtenidos en formularios especiales para la notificación de datos y 3) envío de dichos formularios al coordinador de cada país. Los resultados fueron analizados en función de los procedimientos analíticos y de los países participantes. Los valores de referencia se establecieron por consenso general de todos los participantes después de someterse al método estadístico de truncamiento. El análisis comparado de los resultados mostró coeficientes de variación $(\mathrm{CV})$ de hematocrito $(4,5 \%)$, recuento de glóbulos rojos $(11,0 \%)$ y recuento de glóbulos blancos (22,2\%) más altos que los coeficientes obtenidos en los Estados Unidos de América y Europa. En función del procedimiento analítico, los métodos manuales arrojaron $C V$ mayores que los métodos automatizados. Los datos discriminados por país y por procedimiento analítico, sometidos a un análisis de la varianza (ANOVA), mostraron significación estadística solo para el recuento leucocitario $(\mathrm{P}<0,02)$. Se concluye que el adiestramiento en la preparación de materiales de control de calidad y su utilización posterior en encuestas piloto puede constituir la base inicial para establecer sistemas permanentes de evaluación interna y externa de la calidad en hematología que, junto con la educación continua del personal y la disponibilidad de instrumental automatizado, permitan alcanzar el objetivo de calidad óptima en el laboratorio.

1 Universidad Nacional de La Plata, La Plata, Argentina. Dirección postal: Facultad de Ciencias Exactas, Departamento de Ciencias Biológicas,
Cátedra de Hematología, Calle 47 y 115, 1900 La

Plata, Argentina.

2 Fundación Bioquímica, La Plata, Argentina. 
Los laboratorios clínicos deben producir resultados confiables para asistir a los médicos en el diagnóstico y seguimiento de sus pacientes. Los valores obtenidos en un laboratorio deben ser reproducibles y coherentes tanto al repetir una misma prueba en días distintos como al comparar los resultados con los de laboratorios diferentes (1). Sin embargo, esto no es siempre posible, ya sea debido a técnicas defectuosas (diluciones inexactas, capacitación insuficiente del personal, contaminación de las muestras); a fallas instrumentales (respuesta no lineal, calibración inapropiada, control de temperatura inadecuada, longitud de onda errónea, etc.) o a reactivos inapropiados (caducados, deteriorados, de mala calidad, etc.) (2-18).

Con el propósito de mejorar la calidad de su desempeño, los laboratorios deben implementar programas de control interno y someterse a evaluación externa de la calidad. Todos los laboratorios deben llevar a cabo simultáneamente esas dos actividades complementarias para poder garantizar una calidad analítica aceptable. El control interno significa el seguimiento infalible e inmediato de cada prueba con el fin de garantizar la repetibilidad diaria de los resultados y asegurar que son lo suficientemente confiables para ser divulgados. La evaluación externa se refiere al seguimiento de los resultados de las pruebas por un organismo externo que verifica el desempeño de cada laboratorio y la comparabilidad de resultados entre laboratorios.

El control de la calidad es especialmente importante en el campo de la hematología, porque contribuye a facilitar el diagnóstico preciso de estados patológicos comunes en países en desarrollo e importantes para la salud pública, como las anemias y las discrasias sanguíneas. Por otra parte, es difícil y costoso obtener materiales de referencia, por lo que es conveniente contar con programas de control de calidad en los que se generen materiales apropiados.

En varios países se han organizado programas de alcance local (2), regio- nal (4), nacional (3-5, 7-14, 16-18) e internacional (15) para la evaluación externa de la calidad en hematología. Con pocas excepciones, en América Latina esos programas suelen ser discontinuos, si es que existen. Evidentemente, es necesario poner en práctica programas de evaluación externa de la calidad en hematología en todos los países latinoamericanos.

Con el deseo de avanzar en ese sentido, del 1 al 4 de junio de 1993 se realizó en el Servicio de Hematología del Hospital General de la ciudad de México, DF, un curso sobre esa materia, que contó con el patrocinio de la OPS. El curso, al que concurrieron representantes de siete países latinoamericanos (Argentina, Chile, Cuba, México, Paraguay, República Dominicana y Uruguay), ${ }^{3}$ formó parte de las actividades preliminares del XI Congreso Latinoamericano de Bioquímica Clínica. Ese curso estuvo dirigido a intercambiar experiencias en la preparación total o parcial de materiales de control de calidad en hematología, que permitieran en el futuro sentar las bases para la ejecución de programas de evaluación externa de la calidad o ampliar los ya existentes. Como parte del curso se planeó una encuesta para evaluar el uso de los materiales de control hematológico allí preparados en laboratorios de los siete países participantes. El objetivo del presente trabajo es presentar y analizar los resultados obtenidos por esos laboratorios.

\footnotetext{
Participantes: 1) Argentina: Nilda E. Fink, Facultad de Ciencias Exactas, Universidad Nacional de La Plata y Daniel Mazziotta, Fundación Bioquímica. 2) Chile: Iván Niechi Trujillo, Instituto de Salud Pública. 3) Cuba: Wilfredo Torres, Ministerio de Salud de Cuba. 4) México: Paul Bailleres, Universidad Autónoma de Guerrero; Juan Collazo, Hospital General de México; María Antonieta Garza, Instituto de Servicios de Seguro Social de Trabajadores del Estado (ISSSTE); Mario Gutiérrez, Hospital General de México; Saúl López, Universidad Autónoma de Guerrero; Emma Mendoza, Hospital General de México. 5) Paraguay: Graciela Velázquez de Saldívar, Instituto de Investigaciones en Ciencias de la Salud. 6) República Dominicana: Marina Orsini de Pérez, Universidad Autónoma de Santo Domingo, ISSSTE; Xiomara Peguero, ISSSTE; 7) Uruguay: Stella Raymondo, Universidad de la República.
}

\section{MATERIALES Y MÉTODOS}

La encuesta subregional que aquí se describe sobre la calidad de procedimientos analíticos en hematología se llevó a cabo del 10 al 30 de junio de 1993, en 175 laboratorios ubicados en Argentina, Chile, Cuba, México, Paraguay, República Dominicana y Uruguay. Los laboratorios participantes fueron seleccionados por sorteo. Los tres materiales utilizados en la investigación (solución estándar secundario de cianmetahemoglobina, solución concentrada estabilizada de hemoglobina [lisado] y sangre entera humana preservada) fueron preparados por los participantes en el curso mencionado y distribuidos para realizar la encuesta que se programó como parte del plan de estudios. Con objeto de asegurar una cantidad suficiente de materiales de control para la encuesta, algunos fueron preparados por miembros de la Cátedra de Hematología de la Facultad de Ciencias Exactas de la Universidad Nacional de la Plata, que suelen prepararlos para el Programa de Evaluación Externa de Calidad de la Fundación Bioquímica (PEEC-FB) de la Argentina.

De los tres materiales de control en el conjunto de preparados se tomó al azar una muestra de cada uno de los materiales para distribuir a cada laboratorio participante en coordinación con la correspondiente sociedad profesional nacional. El cuadro 1 indica el número de muestras de preparados de control distribuidas y procesadas en cada país. A todos los laboratorios se les asignaron las siguientes tareas: 1) determinación de hemoglobina, hematocrito, glóbulos rojos y glóbulos blancos en los correspondientes materiales distribuidos, en un plazo no mayor de 3 semanas, de acuerdo con los métodos de uso habitual en cada laboratorio y simultáneamente con muestras de pacientes, las cuales no forman parte de la encuesta; 2) registro de los datos obtenidos con los materiales de control en formularios de notificación elaborados previamente por miembros de la Cátedra de Hematología, y 3) envío de dichos formularios al coordinador de cada país. Los valores de 
CUADRO 1. Número de laboratorios de cada país participante $(n 1)$ y número de muestras de preparados de control procesadas por los laboratorios ( $n 2$ ) en un estudio de la evaluación externa de calidad en hematología en siete países latinoamericanos, junio de 1993

\begin{tabular}{|c|c|c|c|c|c|c|c|c|c|c|c|c|c|c|}
\hline & \multicolumn{2}{|c|}{ País 1} & \multicolumn{2}{|c|}{ País 2} & \multicolumn{2}{|c|}{ País 3} & \multicolumn{2}{|c|}{ País 4} & \multicolumn{2}{|c|}{ País 5} & \multicolumn{2}{|c|}{ País 6} & \multicolumn{2}{|c|}{ País 7} \\
\hline & $n 1$ & $n 2$ & $n 1$ & $n 2$ & $n 1$ & $n 2$ & $n 1$ & $n 2$ & $n 1$ & $n 2$ & $n 1$ & $n 2$ & $n 1$ & $n 2$ \\
\hline $\begin{array}{l}\text { Lisado de hemoglobina } \\
\text { (lote } \mathrm{Hb} / 05 / 93 \text { ) }\end{array}$ & 30 & 6 & 15 & 14 & 30 & 10 & 30 & 13 & 30 & 30 & 30 & 18 & 10 & 8 \\
\hline $\begin{array}{l}\text { Ampolla de HICN } \\
\text { (lote 2002) }\end{array}$ & 30 & 4 & 15 & 15 & 30 & 10 & 30 & 9 & 30 & 27 & 30 & 15 & 10 & 8 \\
\hline $\begin{array}{l}\text { - Hemoglobina } \\
\text { - Hematocrito } \\
\text { - Glóbulos rojos } \\
\text { - Glóbulos blancos }\end{array}$ & $\begin{array}{l}13 \\
13 \\
13 \\
13\end{array}$ & $\begin{array}{l}3 \\
1 \\
1 \\
5\end{array}$ & $\begin{array}{l}9 \\
9 \\
9 \\
9\end{array}$ & $\begin{array}{l}9 \\
2 \\
2 \\
5\end{array}$ & $\begin{array}{l}13 \\
13 \\
13 \\
13\end{array}$ & $\begin{array}{l}10 \\
10 \\
10 \\
10\end{array}$ & $\begin{array}{l}13 \\
13 \\
13 \\
13\end{array}$ & $\begin{array}{l}13 \\
13 \\
12 \\
11\end{array}$ & $\begin{array}{l}13 \\
13 \\
13 \\
13\end{array}$ & $\begin{array}{l}13 \\
13 \\
13 \\
13\end{array}$ & $\begin{array}{l}13 \\
13 \\
13 \\
13\end{array}$ & $\begin{array}{l}7 \\
7 \\
5 \\
7\end{array}$ & $\begin{array}{l}10 \\
10 \\
10 \\
10\end{array}$ & $\begin{array}{l}8 \\
8 \\
8 \\
9\end{array}$ \\
\hline
\end{tabular}

referencia se establecieron por consenso general de todos los participantes después de someterse al método estadístico de truncamiento. ${ }^{4}$

A cada participante del curso se le encomendó la función de coordinar la distribución de las muestras y de los formularios para la recolección posterior de resultados en su país respectivo, en un plazo no mayor de 60 días. Los resultados fueron remitidos al Programa de Evaluación Externa de Calidad de la Fundación Bioquímica (PEEC-FB), donde se realizaron las mediciones estadísticas de posición y dispersión y el análisis de la varianza (ANOVA).

En la preparación de los materiales se emplearon los métodos que se describen a continuación.

\section{Solución estándar secundario de cianmetahemoglobina ( $\mathrm{HICN})$}

Se debe preparar inicialmente una solución de oxihemoglobina $\left(\mathrm{HbO}_{2}\right)$ concentrada, de la siguiente manera: 1) Recolectar aproximadamente $90 \mathrm{~mL}$ de sangre fresca de donante en un

\footnotetext{
4 Este método consiste en calcular el valor promedio y la correspondiente desviación estándar de todos los resultados y luego eliminar todos los que caen fuera de los límites de $\pm 3 \mathrm{DE}$. El proceso se repite hasta que no quede ningún valor atípico o extremo. El promedio de este último grupo es el valor de consenso.
}

frasco cónico de $200 \mathrm{~mL}$, que contenga $20 \mathrm{~mL}$ de citrato de sodio al 3,2\%; lavar los eritrocitos dos veces con solución salina fisiológica; añadir al sedimento globular el doble de su volumen de agua destilada y un volumen de tolueno altamente purificado que equivalga a $40 \%$ del volumen original de los eritrocitos; mezclar los eritrocitos con el líquido y conservar a $4{ }^{\circ} \mathrm{C}$ durante 12 horas. 2) Después de ese período de incubación, centrifugar 15 minutos a $2500 \mathrm{rpm}$. Después de esa centrifugación, la mezcla presenta tres capas claramente diferenciadas: la superior es de tolueno, la intermedia es una suspensión turbia de estroma de eritrocitos y la tercera es la solución de oxihemoglobina clara. Aspirar por completo las dos primeras capas y desecharlas. Filtrar la solución de $\mathrm{HbO}_{2}$ restante a través de papel de filtro libre de cenizas y refrigerar a $4{ }^{\circ} \mathrm{C}$ por no más de 24 horas. 3) Llevar $5 \mathrm{~mL}$ de la solución de $\mathrm{HbO}_{2}$ a un volumen total de 1 litro con una solución que contenga $250 \mathrm{mg}$ de ferricianuro de potasio $\left(\mathrm{K}_{3} \mathrm{Fe}(\mathrm{CN})_{6}\right), 50 \mathrm{mg}$ de cianuro de potasio $(\mathrm{KCN})$ y 1,0 g de bicarbonato de sodio $\left(\mathrm{NaHCO}_{3}\right)$. Esterilizar la solución de HICN así obtenida por filtración y transferir a ampollas de vidrio marrón de $10 \mathrm{~mL}$. Determinar por espectrofotometría la concentración de la solución de HICN en por lo menos 5 ampollas tomadas al azar, usando $\epsilon \mathrm{HICN}($ a $540 \mathrm{~nm})=11,0$ como estándar. Estas determinaciones cons- tituyen un control sobre la homogeneidad de un lote y dan el valor que se imprime en las etiquetas de las ampollas. 4) Incubar 5 ampollas de las soluciones estándar de cada lote de HICN en dos ocasiones con un intervalo de 4 semanas en cultivos por triplicado con medios para control de aerobios (agar sangre, agar chocolate y caldo tioglicolato) y anaerobios (agar Shaedler y caldo tioglicolato enriquecido con hemina y vitamina K) y para el desarrollo de hongos (agar Saboreau). Si no prolifera ningún tipo de microorganismo, el lote se considera estéril microbiológicamente $\mathrm{y}$ se somete a pruebas adicionales. 5) Las ampollas se pueden conservar durante 5 años a $4{ }^{\circ} \mathrm{C}$. Es preciso medir la densidad óptica a $540 \mathrm{~nm}$ de la solución HICN de una ampolla cada 2 semanas. La solución estándar de HICN contiene esencialmente las mismas sustancias sensibles a la luz que el reactivo usado para determinar la conversión de hemoglobina a HICN y, por lo tanto, debe conservarse en la oscuridad (17).

\section{Solución concentrada estabilizada de hemoglobina $(\mathrm{Hb})$ (lisado)}

1) Centrifugar con anticoagulante sangre proveniente de un banco de sangre, con serología negativa al antígeno de superficie de la hepatitis $B$ (HBsAg), virus de la hepatitis C 
(VHC) y virus de la inmunodeficiencia humana (VIH) y separar asépticamente el plasma de la capa blanca (capa de leucocitos o buffy coat). 2) Lavar tres veces con solución salina fisiológica y asegurar la eliminación completa del plasma, los leucocitos y las plaquetas, separando la capa superior del paquete de eritrocitos en cada lavado. 3) Añadir a los eritrocitos lavados la mitad de su volumen de tetracloruro de carbono $\left(\mathrm{CCl}_{3}\right)$, ajustar la tapa de los recipientes y agitarlos vigorosamente en un agitador mecánico durante 1 hora. Refrigerar durante la noche y dejar que los desechos de lípidos y células formen una interfase semisólida entre el tetracloruro de carbono y el lisado. 4) $\mathrm{Al}$ día siguiente, centrifugar a $2500 \mathrm{~g}$ durante 20 minutos; separar las capas superiores de lisado y juntarlas en un frasco limpio. 5) Usando papel de filtro Whatman No. 1 en un embudo de Buchner, filtrar la mezcla de lisados en un matraz con tubuladura lateral conectado a una bomba de succión de agua. 6) Repetir la filtración utilizando papel de filtro Whatman No. 42, cambiando el papel si la filtración es muy lenta; es importante no sobrecargar el embudo con lisado. 7) Por cada $70 \mathrm{~mL}$ de lisado, añadir $30 \mathrm{~mL}$ de glicerol. Después se agregan antibióticos (25-50 mg de penicilina y $25-50 \mathrm{mg}$ de gentamicina por cada $500 \mathrm{~mL}$ de material) y este material se conserva a $4{ }^{\circ} \mathrm{C}$ hasta su utilización. 8) Si se requiere una concentración menor, agregar al lisado concentrado un volumen apropiado de glicerol al $30 \%(\mathrm{v} / \mathrm{v})$ en una solución de $9 \mathrm{~g} / \mathrm{L}$ de cloruro de sodio $(\mathrm{NaCl})$. Mezclar bien. 9) Agitando continuamente, distribuir la mezcla asépticamente en los recipientes estériles, tapar y sellar. Conservado a $4{ }^{\circ} \mathrm{C}$, el producto debe mantener el valor que se le ha asignado durante varios meses. 10) Para la asignación de valor a la concentración de hemoglobina, el método de referencia es el del International Committee for Standardization in Hematology (ICSH), que se describe en un documento de la OMS (19). El CV debe ser menor de $2 \%(20)$.

\section{Sangre entera humana preservada}

1) Recolectar sangre humana exenta de HBsAg, VHC y VIH en bolsas de recolección con citrato fosfato dextrosa (CPD) o dextrosa de citrato ácido (ACD) de donantes del mismo grupo sanguíneo ABO. 2) Pasar la sangre directamente de las bolsas a un matraz de fondo redondo y mezclar por lo menos durante 20 minutos después de haber agregado la última unidad de sangre. 3) Para eliminar los leucocitos, pasar la sangre a través de un filtro para leucocitos (por ejemplo, Sepacell R-500, Ashahi Medical Co. Ltd., Tokio, Japón, u otro similar). 4) Agregar células seudoblancas (células aviares fljadas, véase más adelante) en una cantidad correspondiente a la concentración final deseada. Añadir antibióticos (25-50 mg de penicilina y 25-50 mg de gentamicina por cada $500 \mathrm{~mL}$ de material). 6) Agitando continuamente, distribuir en recipientes estériles, tapar y sellar, y conservar a $4{ }^{\circ} \mathrm{C}$ hasta su uso. 7) Inmediatamente antes de utilizar este material, agitar la muestra con suavidad en un mezclador de rodillo o bien manualmente antes de abrir cada recipiente. Los viales no abiertos de sangre humana se conservan en buenas condiciones durante unas 3 semanas a $4{ }^{\circ} \mathrm{C}$. 8) Para asignar valores a los eritrocitos deben hacerse no menos de 10 recuentos duplicados en 10 alícuotas diferentes del lote en un contador electrónico calibrado (el CV debe ser menor de $2 \%$ ). Los valores de hematocrito deben determinarse por el método de referencia del ICSH (21); (el CV debe ser menor de $2 \%$ ) (19).

\section{Preparación de células seudoblancas}

Los eritrocitos de pollo y de pavo son nucleados y cuando se fijan tienen un tamaño - reconocido por los contadores celulares electrónicos- similar al de los leucocitos humanos. Por esta razón resultan adecuados para actuar como células seudoblancas en sangre entera preservada. Para utilizarlos en el control de leucocitos es suficiente recolectar $25 \mathrm{~mL}$ de sangre, agregarle anticoagulante y proceder de la siguiente forma: 1) Centrifugar la sangre y quitarle el plasma. 2) Añadir a los eritrocitos amortiguador de fosfato monosódico-disódico $0,15 \mathrm{~mol}$ con $\mathrm{pH}$ de 7,4 en cantidad equivalente a tres veces el volumen de sangre. Mezclar y transferir a un frasco de centrifugación; centrifugar y descartar el sobrenadante y la capa blanca. 3) Repetir el lavado y la centrifugación dos veces. 4) Añadir a las células lavadas 10 veces su volumen de glutaraldehído al $0,25 \%$; mezclar vigorosamente para asegurar una resuspensión completa y agitar suavemente en un mezclador mecánico durante 1 hora. Para comprobar si la fijación es completa, centrifugar 2-3 $\mathrm{mL}$ de la suspensión, descartar el sobrenadante, añadir al paquete globular 2-3 $\mathrm{mL}$ de agua destilada, mezclar y centrifugar. Si se produce hemólisis, la fijación está incompleta y puede necesitar más tiempo o reposición del glutaraldehído al 0,25\%. 5) En cuanto se complete la fijación, centrifugar la suspensión y descartar el sobrenadante. 6) Añadir agua destilada (equivalente a tres veces el volumen de sangre original) a los paquetes de células fijadas, resuspender y mezclar por agitación. Centrifugar de nuevo y descartar el sobrenadante; repetir dos veces. 7) Resuspender las células fijadas lavadas a una concentración de aproximadamente $30 \%$ en una solución de $9 \mathrm{~g} / \mathrm{L}$ de $\mathrm{NaCl}$. Mezclar bien y agitar vigorosamente. 8) Realizar un recuento para determinar la concentración apropiada; es aconsejable añadir antibióticos y conservar a $4{ }^{\circ} \mathrm{C}$. 9) Antes de usar, resuspender mediante agitación vigorosa hasta que desaparezcan los grumos del fondo del recipiente; después mezclar durante un mínimo de 20 minutos, en mezclador de rodillos. Si se dispone de sonicación, se aconseja usarla durante 1-2 minutos.

10) Para emplear las células seudoblancas como sustitutos de leucocitos, mezclar según se describió anteriormente y transferir una cantidad apropiada, según la concentración final deseada, a un volumen de la misma sangre preservada de la que por filtración se eliminaron los leucocitos. 11) 
Mezclar bien durante 20 minutos y distribuir en recipientes estériles; tapar y sellar. Se puede conservar por varios meses a $4{ }^{\circ} \mathrm{C}$. 12) Inmediatamente antes de usar, resuspender por agitación manual vigorosa y dejar en un mezclador mecánico por lo menos 15 minutos antes de abrir el tubo. 14) Para asignar valores hay que hacer por lo menos 10 recuentos duplicados en dos alícuotas del lote (el CV debe ser menor de $5 \%)(19)$.

\section{RESULTADOS}

La cantidad de materiales para control de la calidad en hematología distribuidos en cada país participante $(n 1)$ y las respuestas recibidas $(n 2)$ se indican en el cuadro 1, donde se observa que algunos procesaron todas las muestras entregadas, mientras que otros solo lo hicieron parcialmente. El estado de la solución de HICN y del lisado de hemoglobina fue satisfactorio, mientras que la sangre preservada sufrió distintos grados de hemólisis en algunos casos, según la demora en recibir la muestra.

En el cuadro 2 se presenta el conjunto de datos obtenidos de los países para todos los procedimientos realizados. Con respecto a la hemoglobinometría, se observa como dato llamativo la marcada diferencia de los coeficientes de variación obtenidos en la medición de $\mathrm{Hb}$ entre la solución de estándar secundario HICN (CV 10,1\%) y la solución concentrada estabilizada de $\mathrm{Hb}(\mathrm{CV} 9,2 \%)$ por un lado y los valores de sangre entera (CV 3,6\%) por el otro. Con esta última muestra cabría esperar un coeficiente mayor o igual que con los dos materiales anteriores. La variabilidad de los valores restantes -hematocrito $(\mathrm{Ht})$, glóbulos rojos (GR) y glóbulos blancos (GB) - excede los límites tolerables, si se compara, por ejemplo, con los valores medios del CV del Programa de Evaluación Externa de Calidad (EQAS) de Gran Bretaña, que son: $\mathrm{Hb} 1,8$; $\mathrm{Ht} 3,7$; GR 2,$8 ;$ y GB $8,2(22)$.

En el cuadro 3 se discriminan los datos de acuerdo con el procedimiento analítico. En cuanto a los valores de

CUADRO 2. Conjunto de datos de todos los países basados en un estudio de evaluación externa de calidad en hematología en siete países latinoamericanos, junio de 1993

\begin{tabular}{lcccr}
\hline \multicolumn{1}{c}{ Material } & $\begin{array}{c}\text { Tamaño de } \\
\text { la muestra }^{\mathrm{a}}\end{array}$ & $\begin{array}{c}\text { Media } \\
(\overline{\mathrm{x}})\end{array}$ & $\begin{array}{c}\text { Valores } \\
\text { mínimo y máximo }\end{array}$ & CV \\
\hline $\begin{array}{l}\text { Hemoglobina (g/L): lisado } \\
\text { (lote Hb/05/93) }\end{array}$ & 85 & 123,7 & $95,5-199$ & 9,2 \\
$\begin{array}{l}\text { Hemoglobina (g/L): HICN } \\
\text { (lote 2002) }\end{array}$ & 73 & 155,1 & $104-209$ & 10,1 \\
$\begin{array}{l}\text { Sangre preservada } \\
\text { (lote SP/06/93) }\end{array}$ & & & & \\
- Hemoglobina (g/L) & 61 & 153,4 & $142-167$ & 3,6 \\
- Hematocrito (L/L) & 58 & 0,47 & $0,42-0,52$ & 4,5 \\
- Glóbulos rojos (x1012/L) & 53 & 4,9 & $3,05-6,22$ & 11,0 \\
- Glóbulos blancos $\left(\times 10^{9} / \mathrm{L}\right)$ & 60 & 7,3 & $1,3-10,8$ & 22,2 \\
\hline
\end{tabular}

${ }^{a}$ Respuestas emitidas por los laboratorios y expresadas en unidades correctas. $\mathrm{CV}=$ coeficiente de variación.

CUADRO 3. Datos parciales, según procedimiento analítico, obtenidos en una encuesta de evaluación externa de calidad en hematología en siete países latinoamericanos, junio de 1993

\begin{tabular}{|c|c|c|c|c|c|c|}
\hline Material & $\begin{array}{l}\text { Procedi- } \\
\text { miento } \\
\text { analítico }\end{array}$ & $\begin{array}{l}\text { Tamaño de } \\
\text { la muestra }\end{array}$ & Media $(\bar{x})$ & Mediana & CV & $\begin{array}{l}\text { Significación } \\
\text { estadística } \\
(P)\end{array}$ \\
\hline $\begin{array}{l}\text { Hemoglobina }(\mathrm{g} / \mathrm{L}) \text { : lisado } \\
\text { (lote } \mathrm{Hb} / 05 / 93 \text { ) }\end{array}$ & $\begin{array}{l}110 \\
199\end{array}$ & $\begin{array}{r}69 \\
9\end{array}$ & $\begin{array}{l}124,1 \\
121,6\end{array}$ & $\begin{array}{l}123,0 \\
122,0\end{array}$ & $\begin{array}{r}10,0 \\
4,0\end{array}$ & 0,7688 \\
\hline $\begin{array}{l}\text { Hemoglobina (g/L): HICN } \\
\text { (lote 2002) }\end{array}$ & $\begin{array}{l}110 \\
199\end{array}$ & $\begin{array}{r}63 \\
5\end{array}$ & $\begin{array}{l}155,2 \\
149,5\end{array}$ & $\begin{array}{l}157,6 \\
155,0\end{array}$ & $\begin{array}{r}10,5 \\
9,1\end{array}$ & 0,4540 \\
\hline \multicolumn{7}{|l|}{$\begin{array}{l}\text { Sangre preservada } \\
\text { (lote SP/06/93) }\end{array}$} \\
\hline - Hemoglobina (g/L) & $\begin{array}{l}110 \\
199\end{array}$ & $\begin{array}{r}50 \\
8\end{array}$ & $\begin{array}{l}153,2 \\
153,9\end{array}$ & $\begin{array}{l}153,5 \\
152,5\end{array}$ & $\begin{array}{l}3,7 \\
1,8\end{array}$ & 0,5644 \\
\hline - Hematocrito (L/L) & $\begin{array}{l}210 \\
211 \\
220\end{array}$ & $\begin{array}{r}21 \\
3 \\
17\end{array}$ & $\begin{array}{l}0,46 \\
0,49 \\
0,46\end{array}$ & $\begin{array}{l}0,46 \\
0,50 \\
0,46\end{array}$ & $\begin{array}{l}4,2 \\
6,2 \\
3,6\end{array}$ & 0,0326 \\
\hline - Glóbulos rojos (x1012/L) & $\begin{array}{l}310 \\
311\end{array}$ & $\begin{array}{l}27 \\
19\end{array}$ & $\begin{array}{l}4,9 \\
4,8\end{array}$ & $\begin{array}{l}5,0 \\
4,9\end{array}$ & $\begin{array}{l}12,5 \\
10,2\end{array}$ & 0,3779 \\
\hline - Glóbulos blancos (x 109/L) & $\begin{array}{l}410 \\
411\end{array}$ & $\begin{array}{l}33 \\
18\end{array}$ & $\begin{array}{l}7,1 \\
7,8\end{array}$ & $\begin{array}{l}7,4 \\
7,5\end{array}$ & $\begin{array}{l}28,0 \\
13,8\end{array}$ & 0,1460 \\
\hline
\end{tabular}

${ }^{a}$ Respuestas remitidas por los laboratorios, expresadas en unidades correctas y discriminadas por procedimiento analítico. $\mathrm{CV}=$ coeficiente de variación.

Código de procedimientos analíticos:

Hemoglobina $110=$ cianmetahemoglobina; $199=$ otros .

Hematocrito 210 = semiautomatizado por centrifugación.

Microhematocrito 211 = semiautomatizado por centrifugación.

Macrohematocrito $220=$ automatizado.

Glóbulos rojos 310 = recuento manual en cámara de Neubauer; 311 = automatizado.

Glóbulos blancos 410 = recuento manual en cámara de Neubauer; 411 = automatizado.

$\mathrm{Hb}$, los $\mathrm{CV}$ menores corresponden a las determinaciones hechas con equipos automatizados. La significación estadística $(P<0,03)$ entre los métodos empleados para determinar el hematocrito muestra que el método de macrohematocrito semiautomatizado por centrifugación es el que aporta a la sig- 
nificación con la mayor dispersión de datos. También se observa que los CV mayores de los recuentos celulares se relacionan con la utilización de métodos manuales.

En cuanto a la reproducibilidad en los diferentes países (cuadro 4), si bien algunos datos son poco representativos, dado el reducido tamaño de la muestra, el análisis de la varianza no reveló diferencias significativas entre procedimientos, con excepción del recuento leucocitario. En el análisis de la varianza de los recuentos leucocitarios se observa que hay diferencias significativas entre todos los países. Cuando se analizan estos CV en función del grado de automatización por país, parecería que los CV están en relación inversamente proporcional -aunque sin significación estadística $(P<0,7)$ - al número de laboratorios que usan equipos automatizados, que son, para los países 1, 3, 4, 5, 6 y $7: 75 \%$, $33 \%, 64 \%, 19 \%, 43 \%$ y $37 \%$, respectivamente. Los datos del país 2 no se han incluido, porque no estaban discriminados por método.

\section{DISCUSIÓN Y CONCLUSIONES}

El proyecto aquí descrito de preparación de materiales de control de calidad en hematología y su ensayo posterior en una prueba piloto de evaluación externa de la calidad en varios países latinoamericanos es una tentativa regional que puede servir de base para el desarrollo futuro de ese campo en aquellos países que aún no han iniciado programas nacionales o regionales. Al mismo tiempo ha permitido evaluar la calidad actual de las valoraciones hematológicas en algunos laboratorios de países en desarrollo de la Región de las Américas. Sin embargo, su futuro desarrollo requiere contar con infraestructura y recursos económicos y humanos adecuados. Es importante, por ejemplo, disponer de un sistema de distribución apropiado, que impida el deterioro de las muestras, tal como se tuvo en el presente estudio. En caso de no disponerse de cadena de frío, deberían utilizarse los materiales preparados por el Pro-

CUADRO 4. Datos parciales, según país, obtenidos en una encuesta de evaluación externa de calidad en hematología en siete países latinoamericanos, junio de 1993

\begin{tabular}{|c|c|c|c|c|c|}
\hline Material & País & $\begin{array}{l}\text { Tamaño de la } \\
\text { muestra }^{a}\end{array}$ & Media $(\bar{x})$ & CV & $\begin{array}{c}\text { Significación } \\
\text { estadística }(P)\end{array}$ \\
\hline $\begin{array}{l}\text { Hemoglobina }(\mathrm{g} / \mathrm{L}) \text { : lisado } \\
\text { (lote } \mathrm{Hb} / 05 / 93 \text { ) }\end{array}$ & $\begin{array}{l}1 \\
2 \\
3 \\
4 \\
5 \\
6 \\
7\end{array}$ & $\begin{array}{r}6 \\
14 \\
10 \\
13 \\
30 \\
18 \\
8\end{array}$ & $\begin{array}{l}122,6 \\
119,6 \\
125,3 \\
119,2 \\
125,6 \\
124,6 \\
120,5\end{array}$ & $\begin{array}{r}4,0 \\
5,4 \\
3,9 \\
4,6 \\
12,2 \\
9,6 \\
6,4\end{array}$ & 0,5791 \\
\hline $\begin{array}{l}\text { Hemoglobina }(\mathrm{g} / \mathrm{L}) \text { : HICN } \\
\text { (lote 2002) }\end{array}$ & $\begin{array}{l}1 \\
2 \\
3 \\
4 \\
5 \\
6 \\
7\end{array}$ & $\begin{array}{r}4 \\
15 \\
10 \\
9 \\
27 \\
15 \\
8\end{array}$ & $\begin{array}{l}162,9 \\
153,4 \\
157,9 \\
155,2 \\
155,0 \\
151,2 \\
155,2\end{array}$ & $\begin{array}{r}2,3 \\
6,9 \\
4,1 \\
7,8 \\
7,5 \\
14,6 \\
17,5\end{array}$ & 0,8270 \\
\hline $\begin{array}{l}\text { Sangre preservada } \\
\text { (lote SP/06/93) } \\
\text { - Hemoglobina (g/L) }\end{array}$ & $\begin{array}{l}1 \\
2 \\
3 \\
4 \\
5 \\
6 \\
7\end{array}$ & $\begin{array}{c}3 \\
9 \\
10 \\
13 \\
20^{\mathrm{b}} \\
7 \\
8\end{array}$ & $\begin{array}{l}155,7 \\
150,3 \\
153,6 \\
152,1 \\
154,2 \\
155,2 \\
151,0\end{array}$ & $\begin{array}{l}7,2 \\
5,4 \\
3,1 \\
2,6 \\
4,3 \\
2,9 \\
2,7\end{array}$ & 0,5767 \\
\hline - Hematocrito (L/L) & $\begin{array}{l}1^{c} \\
2 \\
3 \\
4 \\
5 \\
6 \\
7\end{array}$ & $\begin{array}{c}- \\
2 \\
10 \\
13 \\
19^{\mathrm{b}} \\
7 \\
8\end{array}$ & $\begin{array}{l}- \\
0,48 \\
0,46 \\
0,47 \\
0,47 \\
0,46 \\
0,46\end{array}$ & $\begin{array}{l}- \\
5,9 \\
3,6 \\
5,9 \\
4,4 \\
5,3 \\
3,5\end{array}$ & 0,9933 \\
\hline $\begin{array}{l}\text { - Glóbulos rojos } \\
\left(\times 10^{12} / \mathrm{L}\right)\end{array}$ & $\begin{array}{l}1^{b} \\
2 \\
3 \\
4 \\
5 \\
6 \\
7\end{array}$ & $\begin{array}{c}- \\
2 \\
10 \\
12 \\
17^{\mathrm{b}} \\
5 \\
8\end{array}$ & $\begin{array}{l}- \\
4,9 \\
4,9 \\
4,9 \\
5,1 \\
4,7 \\
4,5\end{array}$ & $\begin{array}{r}- \\
6,5 \\
7,0 \\
9,7 \\
10,9 \\
2,9 \\
17,9\end{array}$ & 0,2329 \\
\hline $\begin{array}{l}\text { - Glóbulos blancos } \\
\left(\times 10^{9} / \mathrm{L}\right)\end{array}$ & $\begin{array}{l}1 \\
2 \\
3 \\
4 \\
5 \\
6 \\
7\end{array}$ & $\begin{array}{c}5 \\
5 \\
10 \\
11 \\
18^{b} \\
7 \\
9\end{array}$ & $\begin{array}{l}5,8 \\
8,1 \\
8,2 \\
7,9 \\
7,6 \\
6,8 \\
6,4\end{array}$ & $\begin{array}{r}9,0 \\
13,8 \\
20,5 \\
15,1 \\
26,7 \\
8,7 \\
16,7\end{array}$ & 0,0181 \\
\hline
\end{tabular}

$\overline{{ }^{a}}$ Respuestas expresadas en unidades correctas y discriminadas por procedimiento analítico, remitidas por los laboratorios de cada país.

${ }^{b}$ En este país, varias muestras se procesaron en más de un laboratorio.

${ }^{c}$ No se dispuso de los datos individuales.

$\mathrm{CV}=$ coeficiente de variación.

grama Internacional de Evaluación Externa de la Calidad en Hematología de la Organización Mundial de la Salud (OMS) (15).

Del análisis de los resultados obtenidos en este estudio puede concluirse que, en la mayoría de los países parti- cipantes, los estándares de trabajo deben ser mejorados porque los coeficientes de variación (especialmente entre recuentos celulares) son mucho más altos que los que se han registrado en diversos programas $(4,5,7-12$, 14-16, 18). Al compararse los datos 
obtenidos con los valores de referencia del Programa Internacional de Evaluación Externa de la Calidad de la OMS, se observa que el CV obtenido para la medición de $\mathrm{Hb}$ fue de $2,5 \%$, tanto en solución de HICN como en el lisado. Asimismo, para el recuento de leucocitos totales el CV obtenido en el mencionado programa fue de $4,0 \%$ (15). Por el contrario, si se comparan los valores de $\mathrm{Hb}$ obtenidos con la solu- ción de HICN (lote 2002) utilizada en dos estudios del PEEC-FB (17), donde los CV fueron de 11,9 y $8,0 \%$, los valores de la presente encuesta caen dentro de esos límites.

La posibilidad de mejorar la calidad analítica de los laboratorios de la Región estará indudablemente ligada al aumento de actividades de control en cada laboratorio y a la incorporación de instrumental automatizado en los casos en que sea posible. La evaluación externa de la calidad tiene un fuerte impacto docente, pues muestra en forma cuantitativa los errores que se cometen en el trabajo de un laboratorio clínico no controlado y por lo tanto actúa como esqueleto que sostiene las actividades de educación continua dirigidas a alcanzar una calidad analítica óptima.

\section{REFERENCIAS}

1. Castillo de Sánchez ML, Fonseca Yerena ME, eds. Mejoría continua de la calidad: guía para los laboratorios clínicos de América Latina. México: Panamericana; 1995.

2. Vilaseca CG. Estandarización en hematología. En: Actas del Segundo Congreso Argentino de Hematología y Hemoterapia, ciudad de Córdoba, 22 al 26 de noviembre de 1966. Buenos Aires: Sociedad Argentina de Hematología y Hemoterapia, 1967:147-159.

3. Lewis SM, Burgess BJ. Quality in haematology: report of interlaboratory trials in Britain. Br Med J 1969;2:253-256.

4. Koepke JA. The CAP proficiency testing program in hematology. En: Steine AE. Hematology laboratory medicine. Miami: Symposia Specialists; 1974:79-83.

5. Soulier JP, Goguel A. Groupe d'études sur le controle de qualité inter-laboratoires en hématologie. Nov Rev Fran Hematol 1977; 18:648-660.

6. Akiyoshi HT. Control de calidad interlaboratorial en la Argentina: primer programa nacional de encuestas de química clínica realizado por el Comité de Estandarización y Control de Calidad, CECC. Medicina del Atlántico 1978;18:289-294.

7. Rajamaki A. Limits of performance for measurement of blood haemoglobin concentration, number concentration of erythrocytes, and erythrocyte volume fraction in interlaboratory trials: results of the Finnish proficiency testing programme in haematology. Scand J Clin Lab Invest 1980;40: 563-566.
8. Aznar J, Teruel M, Bolufer P. Valoración de los primeros resultados obtenidos en el programa de control de calidad en hematología. Sangre 1982;27:283-290.

9. Gronroos P, Hohenthal U, Karjalainen E, Karjalainen U, Leskinen E, Pikkarainen R, et al. External quality assessment programs in Finland 1971-1983. Sand J Clin Lab Invest 1984; 4 (Suppl 172):179-186.

10. De Leenheer AP, Thienpont LMR. External quality assessment of laboratory performance in haematology in Belgium: analysis of two and a half years' experience. Clin Chim Acta 1984;144:95-103.

11. Villegas A, Álvarez Sala JL, Alarcón C. Resultados del programa de control de calidad en hematología (segunda evaluación). Sangre 1984;29:329-337.

12. Jackson JM, Hughes W. External quality assurance in hematology: the program of the Royal College of Pathologists of Australia. Pathology 1985;17:573-578.

13. Arca M, Gadea F, Hellmers C, Piaggio R. Comisión de Control de Calidad: resúmenes de los trabajos realizados en los últimos seis años 1981-1987. Paraná: Colegio de Bioquímicos de Entre Ríos; 1987.

14. Jou MM, Pastor C, Labal F, Jou C, Vives Corrons JL. Evaluación del primer programa de control de calidad externo en hematología (PCCE-H) de la AEHH: experiencia de un año de funcionamiento. Sangre 1988;34: 14-23.

15. Lewis SM. The WHO International External Quality Assessment Scheme for haematology. Bull World Health Organ 1988;66:283-290.
16. Braga AL, Tutake EM, Nascimento AL, Pelissari CB, Stinghen ST, Malvezzi M, et al. Controle de qualidade externo do eritrograma: uma experiencia en laboratórios de análises clínicas do Estado do Paraná. Rev Bras Anal Clin 1990;22:93-95.

17. Crispiani I, Díaz G, Toro R, Mazziotta D, Fink NE. Evaluación externa de calidad en hematología: hemoglobina (período 1989-1991). Acta Bioquim Clin Latinoam 1993;26:215-225.

18. Fernández Alberti A, Mazziotta D, Fink NE Evaluación de una solución estándar secundario de cianmetahemoglobina. Acta Bioquim Clin Latinoam 1995;29:507-512.

19. World Health Organization. Recommended method for the determination of the haemoglobin content of blood. Geneva: WHO; 1984 (LAB/84.10 rev 1).

20. Lewis SM. Quality assurance in haematology. 2a ed. Geneva: World Health Organization, 1992.

21. International Committee for Standardization in Haematology. Recommendation for reference method for determination by centrifugation of packed cell volume of blood. J Clin Pathol 1980;33:1-2.

22. United Kingdom National External Quality Assessment Schemes. Annual report for 1990. London: Department of Health; 1991.

Manuscrito recibido el 18 de septiembre de 1995 y aceptado para publicación en versión revisada el 7 de octubre de 1996. 
ABSTRACT The assurance of analytical quality in a clinical laboratory is achieved through an internal system of quality control complemented by an external evaluation program. Quality assurance provides a foundation for the confidence that is placed

External evaluation of analytical quality in hematology: a necessity in Latin America in laboratory results and their use in the diagnosis and treatment of diseases.

Many laboratories in Latin American countries do not have appropriate systems in place to evaluate and control quality. Given the importance of diagnoses based on hematologic data, the Pan American Health Organization sponsored a course in quality control in hematology during the XI Latin American Congress of Clinical Biochemistry (Mexico, 1993), in which representatives from Argentina, Chile, Cuba, Mexico, Paraguay, Dominican Republic, and Uruguay participated. As part of the course, the following control materials were produced: secondary standard solution of cyanmethemoglobin, stabilized concentrated hemoglobin solution, and preserved human whole blood with pseudoleukocytes. These materials were sent to laboratories in the seven participating countries for use in analytical procedures, and the results were then subjected to an external evaluation to assess individual performance and the comparability of results among the group. The specific tasks carried out were: (1) determination of values for hemoglobin, hematocrit, and red and white blood cell counts by the procedures normally used in each laboratory; (2) recording of the data on special reporting forms; and (3) transmittal of those forms to the coordinator in each country. The results were analyzed with regard to both the procedure used and the participating country. Reference values were established by consensus following application of a statistical method to eliminate outlying values. Comparative analysis of the results showed the coefficients of variation $(\mathrm{CV})$ of the hematocrit $(4.5 \%)$, red blood cell count $(11.0 \%)$, and white blood cell count $(22.2 \%)$ to be higher than those reported from the United States of America and Europe. With regard to analytical procedures, the manual methods yielded larger CV than the automated methods. When analysis of variance (ANOVA) was used on data broken down by country and by procedure, the only statistically significant result was for leukocyte count $(P<0.02)$. It was concluded that training in the preparation of quality control materials and the subsequent use of these materials in pilot surveys could provide a starting point for establishing continuous internal and external quality assessment systems in hematology. Such systems, together with continuing education for laboratory personnel and the availablity of automated instrumentation, will lead to achievement of optimum laboratory quality. 